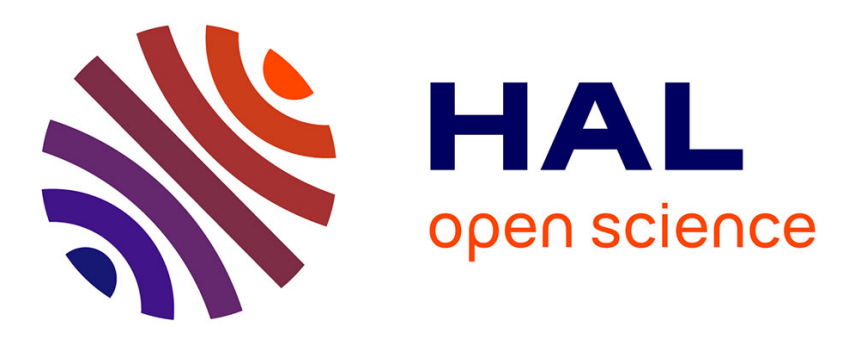

\title{
Influence of molecular mass, thermal treatment and nucleating agent on structure and fracture toughness of isotactic polypropylene
}

\author{
M. Avella, Ramiro Dell'Erba, E. Martuscelli, G. Ragosta
}

\section{- To cite this version:}

M. Avella, Ramiro Dell'Erba, E. Martuscelli, G. Ragosta. Influence of molecular mass, thermal treatment and nucleating agent on structure and fracture toughness of isotactic polypropylene. Polymer, 1993, 34 (14), pp.2951-2960. 10.1016/0032-3861(93)90620-p . hal-01980049

\section{HAL Id: hal-01980049 \\ https://hal.science/hal-01980049}

Submitted on 14 Jan 2019

HAL is a multi-disciplinary open access archive for the deposit and dissemination of scientific research documents, whether they are published or not. The documents may come from teaching and research institutions in France or abroad, or from public or private research centers.
L'archive ouverte pluridisciplinaire HAL, est destinée au dépôt et à la diffusion de documents scientifiques de niveau recherche, publiés ou non, émanant des établissements d'enseignement et de recherche français ou étrangers, des laboratoires publics ou privés. 


\section{ENEA}

Italian National Agency for New Technologies, Energy and Sustainable Economic Development

http://www.enea.it/en

http://robotica.casaccia.enea.it/index.php?lang=en

This paper is a draft. The paper is available on:

Polymer „Influence of molecular mass, thermal treatment and nucleating agent on structrure and fracture toughness of isotactic polypropylene“. M.Avella, R. dell'Erba, G. Ragosta and E.

Martuscelli V. 34, n.14 p.2951-60 (1993). https://doi.org/ 10.1016/0032-3861(93)90620-P 


\title{
Influence of molecular mass, thermal treatment and nucleating agent on structure and fracture toughness of isotactic polypropylene
}

\author{
M. Avella, R. dell'Erba, E. Martuscelli* and G. Ragosta \\ Istituto di Ricerche su Tecnologia dei Polimeri e Reologia, CNR, Via Toiano 6, Arco \\ Felice 80072, Napoli, Italy
}

\begin{abstract}
The influence of processing, crystallization conditions and molecular characteristics on the fracture behaviour of isotactic polypropylene obtained by a new catalyst system was investigated. The sample specimens were prepared by using two extreme crystallization conditions - quenching or slow crystallization - in order to obtain crystals and amorphous phases with different structure. Interesting correlations between fracture parameters and some morphological parameters such as long spacing and lamellar thickness of the samples were found. The SEM fractographic analysis provides useful information on the influence of factors such as molecular weight, spherulite size and undercooling. Nucleating agents were used to tailor the dimensions of spherulites.
\end{abstract}

(Keywords: fracture toughness; polypropylene; thermal treatment)

\section{INTRODUCTION}

In a previous paper $^{1}$ we reported the results of an investigation concerning the influence of molecular weight $\left(M_{\mathrm{w}}\right)$ on the nucleation density, overall kinetics of crystallization and thermal behaviour of isotactic polypropylene (iPP) samples obtained by a new catalyst system. This catalyst process allows the production of iPP fractions with higher control of isotacticity index (up to $99 \%$ ), molecular weight and molecular weight distribution ${ }^{2}$.

In this contribution the same iPP samples were used to study the effects of crystallization conditions and $M_{\mathrm{w}}$ on the fracture behaviour at high strain rate of such materials. The iPP samples were prepared by using different thermal treatments (quenching and isothermal crystallization) to obtain specimens with very different crystallinity, crystal morphological and lamellar thickness of crystals. Furthermore, a nucleating agent was used to obtain iPP spherulites with tailored dimensions.

The aim of this work was to correlate the fracture parameters with the different microstructures obtained, in order to provide useful information on the mechanism through which the various molecular and structural elements forming the spherulites control the growth and the propagation of cracks. For this purpose, the high-speed fracture data were analysed using the linear elastic fracture mechanics theory. The parameters of this theory, such as the critical strain energy release rate $\left(G_{c}\right)$ and the critical strain intensity factor $\left(K_{c}\right)$, are particularly suitable for monitoring morphological and structural

\footnotetext{
* To whom correspondence should be addressed
}

changes in the material. A fractographic analysis by means of scanning electron microscopy (SEM) was also performed.

\section{EXPERIMENTAL}

\section{Materials}

A series of iPP samples (Himont-Italia Spa) with different molar mass and molar mass distribution were used in the present work. Their molecular characteristics, code numbers and trade names are reported in Table 1.

\section{Specimen preparation}

A sample of polymer was placed between two Teflon sheets and laterally contained in a $3.5 \mathrm{~mm}$ thick steel frame. The whole system was inserted within the plates of a hydraulic press heated at $200^{\circ} \mathrm{C}$ and kept for 10 min without any applied pressure, to allow complete melting. After this period a pressure of $10 \mathrm{MPa}$ was applied for $5 \mathrm{~min}$. Then the pressure was released and the samples were quenched in ice and water at about $0^{\circ} \mathrm{C}$. After the compression moulding some samples (iPP1, iPP4 and iPP6) were also immersed in a thermostat-controlled bath which was set at a predetermined temperature to ensure crystallization. The crystallization temperatures were selected in order to achieve the same values of undercooling $(\Delta T)$ for the three different polymers defined as:

$$
\Delta T=T_{\mathrm{m}}-T_{\mathrm{c}}
$$

where $T_{\mathrm{c}}$ is the crystallization temperature and $T_{\mathrm{m}}$ is the equilibrium melting temperature (the $T_{\mathrm{m}}$ of all iPP samples was determined in a previous paper ${ }^{1}$ ). The values of $\Delta T$ used are listed in Table 2 . In a different procedure 
Table 1 Molecular characteristics of polypropylene samples

\begin{tabular}{lllll}
\hline Sample & Trade name & $\begin{array}{l}M_{\mathrm{w}} \\
\left(\times 10^{5}\right)\end{array}$ & $\begin{array}{l}M_{\mathrm{n}} \\
\left(\times 10^{4}\right)\end{array}$ & $M_{\mathrm{w}} / M_{\mathrm{n}}$ \\
\hline iPP1 & Valtec 302 & 1.1 & 1.7 & 6.4 \\
iPP2 & Valtec 298 & 1.7 & 1.8 & 9.6 \\
iPP3 & Valtec HS 013 & 3.1 & 4.5 & 7.0 \\
iPP4 & Valtec HS 010 & 3.6 & 5.3 & 6.8 \\
iPP5 & Valtec HS 005 & 4.5 & 6.6 & 6.7 \\
iPP6 & Valtec HL 002 & 7.3 & 9.1 & 8.0 \\
\hline
\end{tabular}

Table 2 Crystallization temperatures $\left(T_{c}\right)$, equilibrium melting temperatures $\left(T_{\mathrm{m}}\right)$ and undercoolings $(\Delta T)$ used to prepare the isothermally crystallized iPP samples

\begin{tabular}{llll}
\hline Sample & $\begin{array}{c}T_{\mathrm{c}} \\
\left({ }^{\circ} \mathrm{C}\right)\end{array}$ & $\begin{array}{l}T_{\mathrm{m}} \\
\left({ }^{\circ} \mathrm{C}\right)\end{array}$ & $\begin{array}{c}\Delta T \\
\left({ }^{\circ} \mathrm{C}\right)\end{array}$ \\
\hline iPP1 & 127 & 182 & 55 \\
& 122 & 182 & 60 \\
iPP4 & 117 & 182 & 65 \\
& 130 & 185 & 55 \\
iPP6 & 125 & 185 & 60 \\
& 120 & 185 & 65 \\
& 137 & 192 & 55 \\
& 132 & 192 & 60 \\
& 127 & 192 & 65 \\
\hline
\end{tabular}

the iPP1, iPP4 and iPP6 samples were premixed with $1 \mathrm{wt} \%$ of nucleant (sodium benzoate) by means of a Brabender-like apparatus.

Rectangular specimens were cut from the crystallized sheets for performing Charpy impact tests. Prior to testing, the samples were notched as follows: first a blunt notch was produced using a machine with a V-shaped tool and then a sharp notch $0.2 \mathrm{~mm}$ deep was made by a razor blade fixed to a micrometric apparatus. The final notch depth was measured after fracture, using an optical microscope.

\section{Thermal analysis}

The apparent melting temperature $\left(T_{\mathrm{m}}^{\prime}\right)$ and the crystallinity index $\left(X_{c}\right)$ for all the iPP samples, prepared both by quenching and isothermal crystallization, were determined by differential scanning calorimetry (d.s.c.) using a Mettler TA-3000 equipped with a controller and a programming unit (microprocessor TC-10). All the measurements on the samples (about $8-10 \mathrm{mg}$ ) were tested using a scan rate of $10^{\circ} \mathrm{C} \mathrm{min}^{-1}$. The values of $T_{\mathrm{m}}^{\prime}$ and the apparent enthalpy $\left(\Delta H^{*}\right)$ were obtained from the maxima and the area of the melting peaks, respectively. The $X_{c}$ values of iPP samples were calculated by the following relation:

$$
X_{\mathrm{c}}=\Delta H^{*} / \Delta H^{\circ}
$$

where $\Delta H^{\circ}$ is the heat of fusion per $\mathrm{g}$ of $100 \%$ crystalline iPP, taken as $209 \mathrm{~J} \mathrm{~g}^{-1}$ (ref. 3).

\section{$S A X S$ measurements}

Small angle X-ray scattering (SAXS) measurements were performed on quenched and isothermally crystallized iPP samples using a compact Kratky camera equipped with a Braun one-dimensional position-sensitive detector. $\mathrm{Ni}$-filtered $\mathrm{CuK} \alpha$ radiation, generated from a Philips $\mathrm{X}$-ray generator (PW 1730/10) operating at $40 \mathrm{kV}$ and $30 \mu \mathrm{A}$ was used. The row scattering data were corrected for parasitic scattering, absorption and slit smearing by Glatter's method ${ }^{4}$. The desmeared intensities were corrected with the Lorentz factor ${ }^{5}$ by multiplying by $S^{2}$ ( $S=2 / \lambda \sin \theta ; S$ is the scattering vector).

\section{Impact fracture measurements}

Fracture tests were carried out on a Charpy Instrumented Pendulum machine at an impact speed of $1 \mathrm{~m} \mathrm{~s}^{-1}$. Samples with a notch depth to width ratio of 0.3 and a span length of $48 \mathrm{~mm}$ were fractured at room temperature. The relative curves of energy and load plotted against time or displacement were recorded.

\section{Fracture toughness parameters}

The impact data were analysed according to the linear elastic fracture mechanics approach ${ }^{6}$. From this approach two parameters can be determined which accurately describe the conditions for the onset of crack growth in the material. One parameter is the stress intensity factor $K$, which determines the distribution of stress ahead of the crack tip. The fracture occurs when $K$ achieves a critical value $K_{\mathrm{c}}$ given by:

$$
K_{\mathrm{c}}=\sigma Y a^{1 / 2}
$$

where $\sigma$ is the nominal stress at the onset of crack propagation, $a$ is the initial crack length and $Y$ is a calibration factor dependent on the specimen geometry. For single cracked bent specimens, $Y$ is given by Brown and Srawley ${ }^{7}$. The other parameter is the critical strain energy release rate $G_{c}$, which represents the energy necessary to initiate crack propagation. This can be expressed in terms of fracture energy by:

$$
G_{\mathrm{c}}=U / B W \Phi
$$

where $U$ is the fracture energy corrected for the kinetic energy contribution, $B$ and $W$ are the thickness and width of the specimen, respectively, and $\Phi$ is a calibration factor which depends on the length of the crack and the size of the sample. The values of $\Phi$ were taken from Plati and Williams ${ }^{8}$.

\section{Fractography}

Fracture surfaces of notched specimens were examined using a Philips 501 scanning electron microscope, after coating the broken surfaces with a thin layer of gold-palladium alloy.

\section{RESULTS AND DISCUSSION}

\section{Thermal properties}

Table 3 reports the apparent melting temperature $\left(T_{\mathrm{m}}^{\prime}\right)$ and crystallinity index $\left(X_{\mathrm{c}}\right)$ for quenched iPP samples. These values decrease with increasing molecular weight

Table 3 Apparent melting temperatures $\left(T_{\mathrm{m}}^{\prime}\right)$ and crystallinity index $\left(X_{c}\right)$ for quenched iPP samples

\begin{tabular}{lll}
\hline Sample & $\begin{array}{c}T_{\mathrm{m}}^{\prime} \\
\left({ }^{\circ} \mathbf{C}\right)\end{array}$ & $\begin{array}{l}\boldsymbol{X}_{\mathrm{c}} \\
(\%)\end{array}$ \\
\hline iPP1 & 169 & 42 \\
iPP2 & 168 & 40 \\
iPP3 & 166 & 39 \\
iPP4 & 166 & 36 \\
iPP5 & 166 & 36 \\
iPP6 & 162 & 34 \\
\hline
\end{tabular}


of iPP, indicating that the amorphous material increases with increasing $M_{\mathrm{w}}$.

The thermal parameters $\left(T_{\mathrm{m}}^{\prime}\right.$ and $\left.X_{\mathrm{c}}\right)$ for iPP samples isothermally crystallized at different $\Delta T$ values, with and without nucleating agent, are reported in Table 4. As expected, for all samples examined $T_{\mathrm{m}}^{\prime}$ and $X_{\mathrm{c}}$ values increase with decreasing $\Delta T$ (increasing $T_{\mathrm{c}}$ ). Furthermore at fixed $\Delta T$, the $T_{\mathrm{m}}^{\prime}$ points seem to decrease slightly with

Table 4 Thermal parameters obtained for isothermally crystallized iPP samples

\begin{tabular}{|c|c|c|c|c|c|c|c|c|}
\hline \multirow[b]{2}{*}{ Sample } & \multicolumn{4}{|c|}{ Without nucleating agent } & \multicolumn{4}{|c|}{ With nucleating agent } \\
\hline & $\begin{array}{l}T_{c} \\
\left({ }^{\circ} \mathrm{C}\right)\end{array}$ & $\begin{array}{l}\Delta T \\
\left({ }^{\circ} \mathrm{C}\right)\end{array}$ & $\begin{array}{l}T_{\mathrm{m}}^{\prime} \\
\left({ }^{\circ} \mathrm{C}\right)\end{array}$ & $\begin{array}{l}X_{\mathrm{c}} \\
(\%)\end{array}$ & $\begin{array}{l}T_{c} \\
\left({ }^{\circ} \mathrm{C}\right)\end{array}$ & $\begin{array}{l}\Delta T \\
\left({ }^{\circ} \mathrm{C}\right)\end{array}$ & $\begin{array}{l}T_{\mathrm{m}}^{\prime} \\
\left({ }^{\circ} \mathrm{C}\right)\end{array}$ & $\begin{array}{l}X_{\mathrm{c}} \\
(\%)\end{array}$ \\
\hline \multirow[t]{3}{*}{ iPP1 } & 117 & 65 & 166 & 46 & 117 & 65 & 166 & 47 \\
\hline & 122 & 60 & 168 & 48 & 122 & 60 & 167 & 50 \\
\hline & 127 & 55 & 169 & 52 & 127 & 55 & 168 & 50 \\
\hline \multirow[t]{3}{*}{ iPP4 } & 120 & 65 & 166 & 43 & 120 & 65 & 167 & 39 \\
\hline & 125 & 60 & 167 & 44 & 125 & 60 & 167 & 40 \\
\hline & 130 & 55 & 169 & 46 & 130 & 55 & 169 & 41 \\
\hline \multirow[t]{3}{*}{ iPP6 } & 127 & 65 & 164 & 36 & 127 & 65 & 163 & 35 \\
\hline & 132 & 60 & 165 & 37 & 132 & 60 & 165 & 36 \\
\hline & 137 & 55 & 166 & 39 & 137 & 55 & 165 & 36 \\
\hline
\end{tabular}
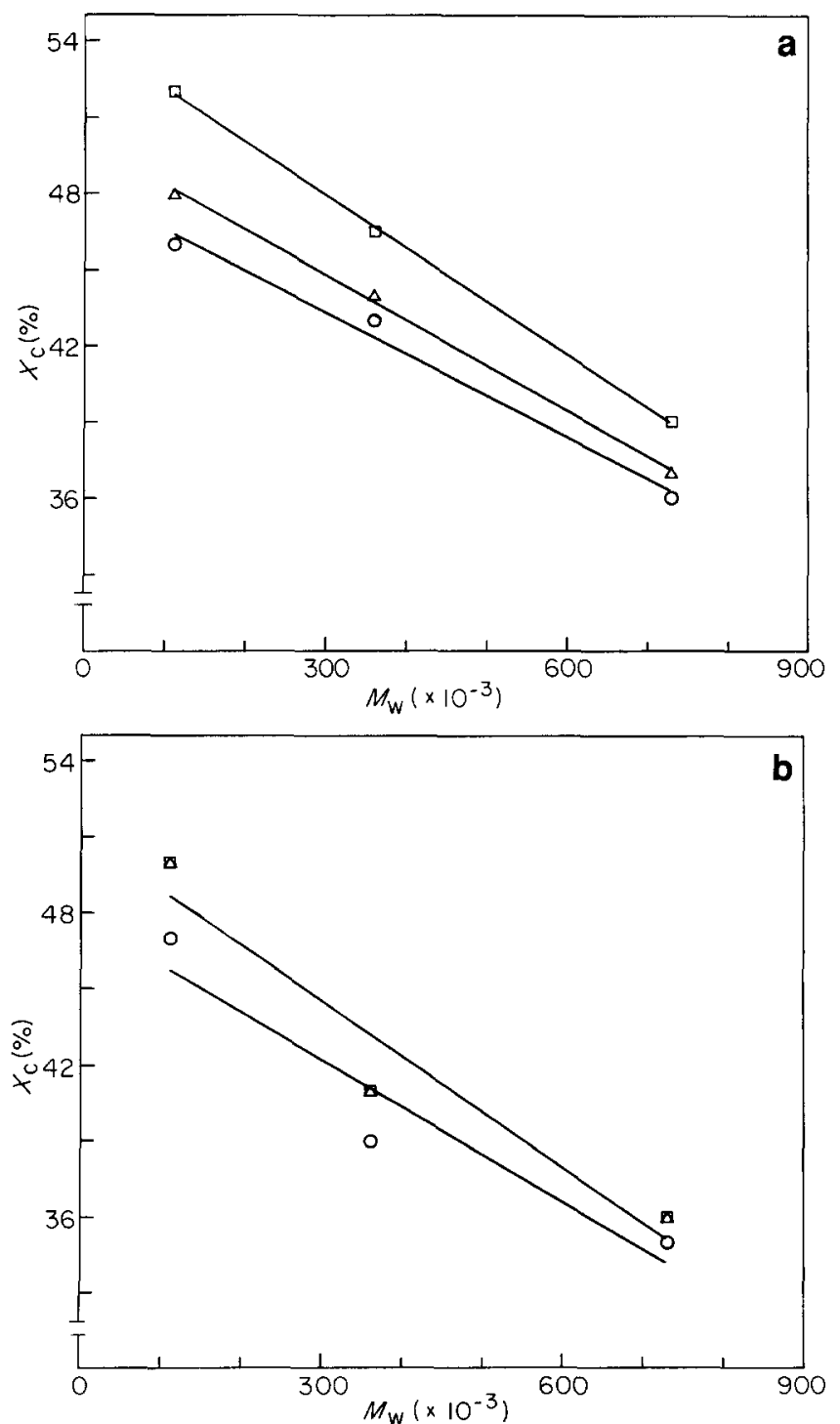

Figure 1 Crystallinity index as a function of molecular weight for iPP samples (a) without nucleating agent and (b) containing sodium benzoate as nucleating agent. $\Delta T$ values: $O, 65^{\circ} \mathrm{C} ; \triangle, 60^{\circ} \mathrm{C} ; \square, 55^{\circ} \mathrm{C}$ increase in $M_{\mathrm{w}}$, while a strong depression of $X_{\mathrm{c}}$ values was observed (Figure la). The dependence of $X_{c}$ on the molecular weight of iPP can be attributed to a higher amount of chain entanglements. This is enhanced with increasing molecular weight, giving rise to a more disordered crystallization process and consequently $X_{\mathrm{c}}$ decreases. A similar $X_{\mathrm{c}}$ depression as a function of molecular weight, at given $\Delta T$, is also seen in the case of isothermally crystallized iPP containing nucleating agent (Table 4 and Figure 1 b). This suggests that the nucleating agent influences only the size of spherulites and not the final crystallinity. In fact, for all the iPP samples in the $\Delta T$ range examined the $X_{\mathrm{c}}$ value seems to be almost constant (Table 4). This is due to the action of the nucleating agent which promotes rapid crystallization of the material at low $\Delta T$ and thus produces the same degree of crystallinity independently of the $\Delta T$ used.

\section{$S A X S$ results}

A typical Lorentz-corrected desmeared pattern for an isothermally crystallized iPP sample is shown in Figure 2. The SAXS profile exhibits a well-defined maximum. By applying Bragg's law, the long period $L$ was obtained for all samples examined, as a function of molecular weight. For the isothermally crystallized samples $L$ was also calculated as a function of $T_{\mathrm{c}}$ and $\Delta T$.

Assuming a two-phase model for the iPP spherulite fibrillae, i.e. alternating parallel crystalline lamellae and amorphous layers, the crystalline lamellar thickness $L_{c}$ was calculated from $L$ values using the following equation ${ }^{9}$ :

$$
L_{\mathrm{c}}=X_{\mathrm{c}} L /\left[\left(\rho_{\mathrm{c}} / \rho_{\mathrm{a}}\right)\left(1-X_{\mathrm{c}}\right)+X_{\mathrm{c}}\right]
$$

where $X_{\mathrm{c}}$ is the d.s.c. crystallinity index, $\rho_{\mathrm{c}}$ and $\rho_{\mathrm{a}}$ are the density of the crystalline and amorphous iPP phases, respectively. The values used for the densities were ${ }^{3}$ : $\rho_{\mathrm{c}}=0.937 \mathrm{~g} \mathrm{~cm}^{-3}$ and $\rho_{\mathrm{a}}=0.852 \mathrm{~g} \mathrm{~cm}^{-3}$. Subtracting the $L_{\mathrm{c}}$ from the $L$ values the thickness of the amorphous length $L_{\mathrm{a}}$ was obtained. The results of SAXS analysis are summarized in Tables 5 and 6 . In the case of quenched samples (Table 5) it is found that $L$ increases with increase in $M_{\mathrm{w}}$. This can easily be ascribed to the increase in $L_{\mathrm{a}}$; in fact the $L_{c}$ values seem to be almost constant.

In the case of samples isothermally crystallized (without nucleating agents) the SAXS parameters $\left(L, L_{\mathrm{c}}\right.$ and $L_{\mathrm{a}}$ ) increase with increasing $T_{\mathrm{c}}$ (decreasing $\Delta T$ ), as

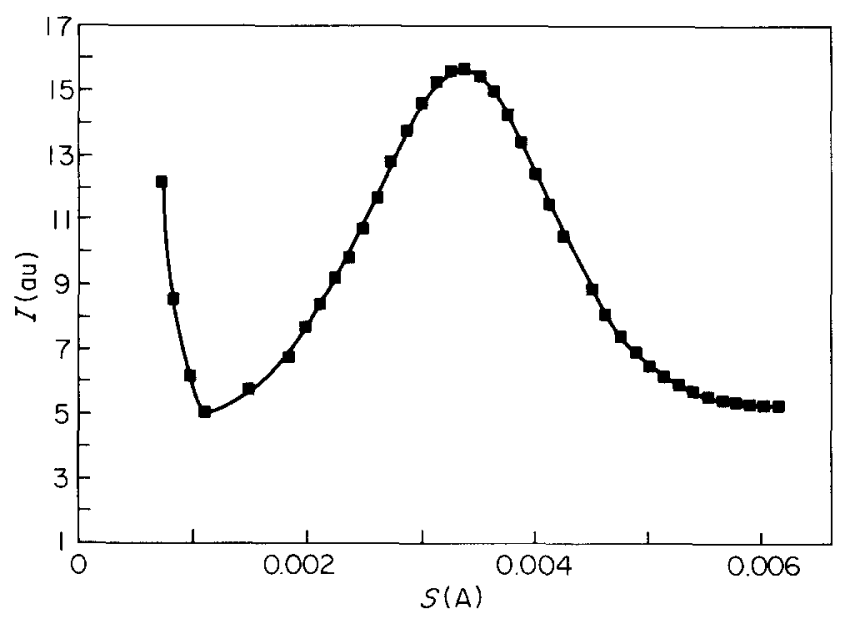

Figure 2 Typical SAXS Lorentz-corrected desmeared intensity $I$ versus $S$ patterns for an isothermally crystallized iPP sample 
Table 5 SAXS parameters calculated for quenched iPP samples

\begin{tabular}{llll}
\hline Sample & $\begin{array}{l}L \\
(\AA)\end{array}$ & $\begin{array}{l}L_{\mathrm{c}} \\
(\AA)\end{array}$ & $\begin{array}{l}L_{\mathrm{a}} \\
(\AA)\end{array}$ \\
\hline iPP1 & 106 & 36 & 70 \\
iPP2 & 113 & 37 & 76 \\
iPP3 & 110 & 40 & 70 \\
iPP4 & 120 & 40 & 80 \\
iPP5 & 122 & 41 & 81 \\
iPP6 & 124 & 40 & 84 \\
\hline
\end{tabular}

Table 6 SAXS parameters calculated for isothermally crystallized iPP samples

\begin{tabular}{|c|c|c|c|c|c|c|c|c|c|c|}
\hline \multirow[b]{2}{*}{ Sample } & \multicolumn{5}{|c|}{ Without nucleating agent } & \multicolumn{5}{|c|}{ With nucleating agent } \\
\hline & $\begin{array}{l}T_{\mathrm{c}} \\
\left({ }^{\circ} \mathrm{C}\right)\end{array}$ & $\begin{array}{l}\Delta T \\
\left({ }^{\circ} \mathrm{C}\right)\end{array}$ & $\begin{array}{l}L \\
(\AA)\end{array}$ & $\begin{array}{l}L_{\mathrm{c}} \\
(\AA)\end{array}$ & $\begin{array}{l}L_{\mathrm{a}} \\
(\AA)\end{array}$ & $\begin{array}{l}T_{\mathrm{c}} \\
\left({ }^{\circ} \mathrm{C}\right)\end{array}$ & $\begin{array}{l}\Delta T \\
\left({ }^{\circ} \mathrm{C}\right)\end{array}$ & $\begin{array}{l}L \\
(\AA)\end{array}$ & $\begin{array}{l}L_{c} \\
(\AA)\end{array}$ & $\begin{array}{l}L_{\mathrm{q}} \\
(\AA)\end{array}$ \\
\hline \multirow[t]{3}{*}{ iPP1 } & 117 & 65 & 164 & 71 & 93 & 117 & 65 & 171 & 72 & 99 \\
\hline & 122 & 60 & 163 & 74 & 89 & 122 & 60 & 178 & 75 & 103 \\
\hline & 127 & 55 & 200 & 90 & 110 & 127 & 55 & 187 & 87 & 103 \\
\hline \multirow[t]{3}{*}{ iPP4 } & 120 & 65 & 177 & 73 & 104 & 120 & 65 & 194 & 72 & 122 \\
\hline & 125 & 60 & 179 & 75 & 104 & 125 & 60 & 201 & 76 & 125 \\
\hline & 130 & 55 & 210 & 93 & 117 & 130 & 55 & 227 & 88 & 125 \\
\hline \multirow[t]{3}{*}{ iPP6 } & 127 & 65 & 224 & 76 & 148 & 127 & 65 & 221 & 73 & 138 \\
\hline & 132 & 60 & 228 & 79 & 148 & 132 & 60 & 230 & 79 & 151 \\
\hline & 137 & 55 & 261 & 96 & 165 & 137 & 55 & 284 & 97 & 187 \\
\hline
\end{tabular}
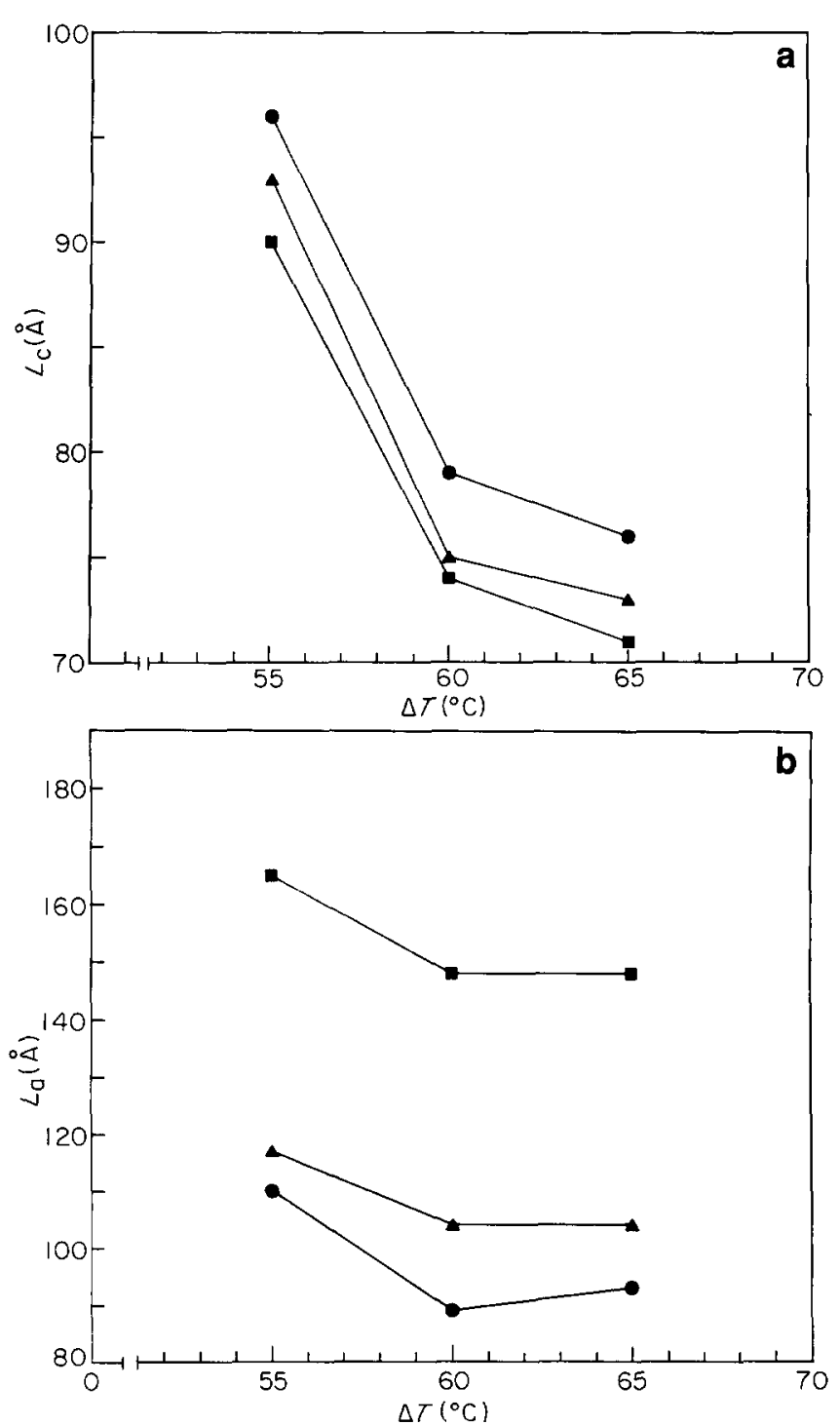

Figure 3 (a) Crystal lamellar thickness and (b) amorphous lamellar thickness for iPP samples as a function of undercooling. , iPP1; $\boldsymbol{\Delta}$, iPP4; $\square$, iPP6
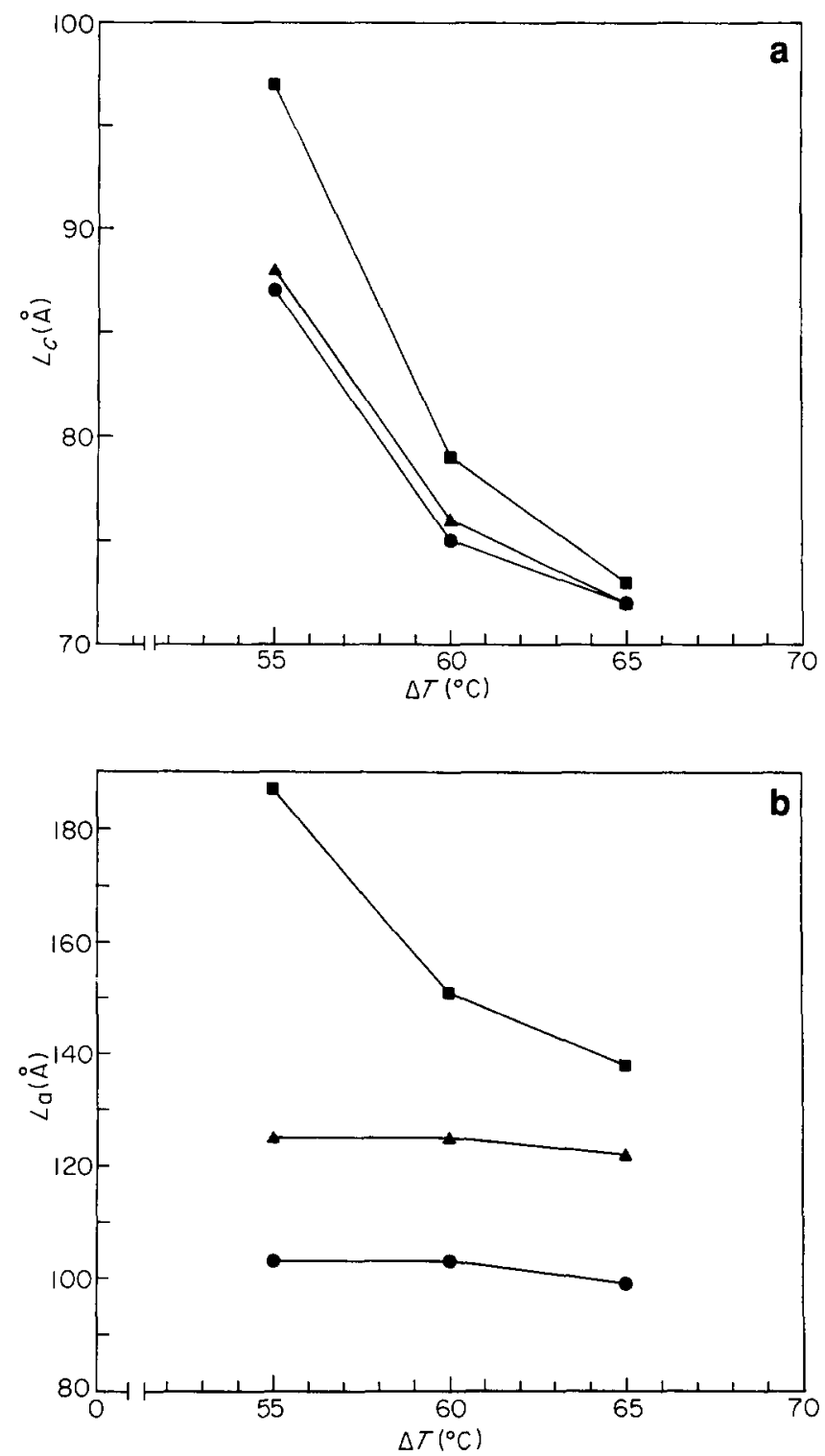

Figure 4 (a) Crystal lamellar thickness and (b) amorphous lamellar thickness for iPP samples containing sodium benzoate as nucleating agent, as a function of undercooling. - iPP1; $\boldsymbol{\Lambda}$, iPP4; $\mathbf{\square}$, iPP6

expected (see Table 6 and also Figures $3 a$ and $b$ where $L_{\mathrm{c}}$ and $L_{\mathrm{a}}$ values, respectively, are plotted as a function of $\Delta T$ ). From these figures it is evident that $L_{\mathrm{c}}$ and $L_{\mathrm{a}}$ values, for a given $\Delta T$, are affected by $M_{w}$. In fact, both $L_{\mathrm{c}}$ and $L_{\mathrm{a}}$ increase with $M_{\mathrm{w}}$, the effects being more pronounced for $L_{\mathrm{a}}$ than $L_{\mathrm{c}}$. Similar behaviour was also observed for samples isothermally crystallized in the presence of the nucleating agent (see Table 6 and also Figures $4 a$ and $4 b$ where $L_{c}$ and $L_{a}$, respectively, are plotted against $\Delta T$ ). Also in this case $L, L_{\mathrm{c}}$ and $L_{\mathrm{a}}$ increase with increasing $T_{c}$ (decreasing $\Delta T$ ) and seem to be dependent on the $M_{w}$ of iPP. However, it can be noted that the $L_{\mathrm{c}}$ values obtained at the highest $\Delta T$ (see Figure $4 a)$ seem to be almost constant, indicating the formation of lamellar crystals of the same thickness independently of the iPP molecular weight.

\section{Fracture toughness and fractography}

The critical strain energy release rate $G_{\mathrm{c}}$ and the critical stress factor $K_{\mathrm{c}}$ for quenched iPP samples, calculated according to equations (1) and (2), are shown as a function of $M_{\mathrm{w}}$ in Figures 5 and 6 , respectively. Both $G_{\mathrm{c}}$ and $K_{\mathrm{c}}$ 


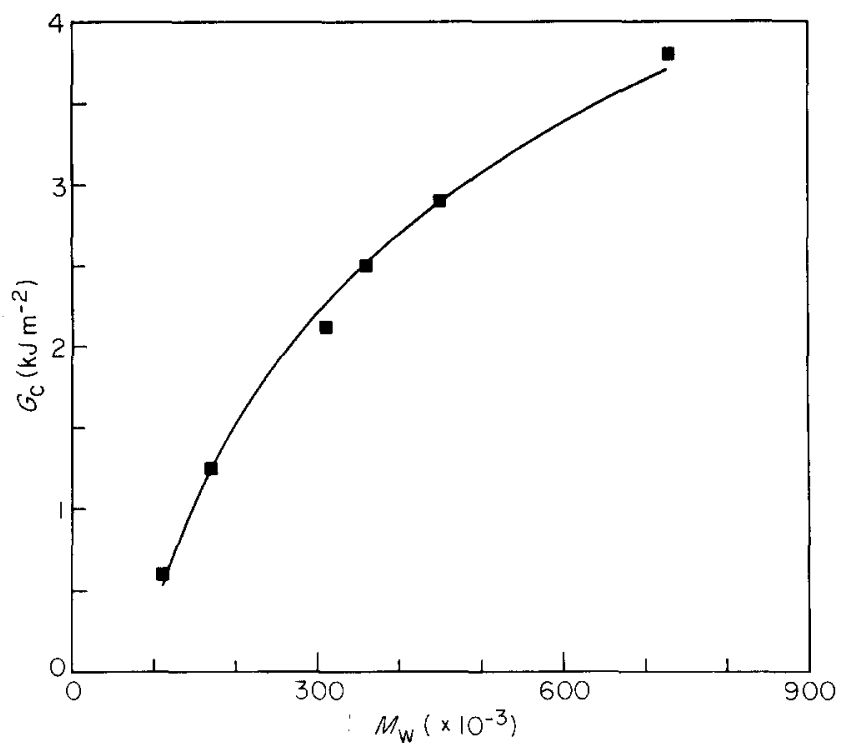

Figure 5 Critical strain energy release rate as a function of molecular weight for quenched iPP samples

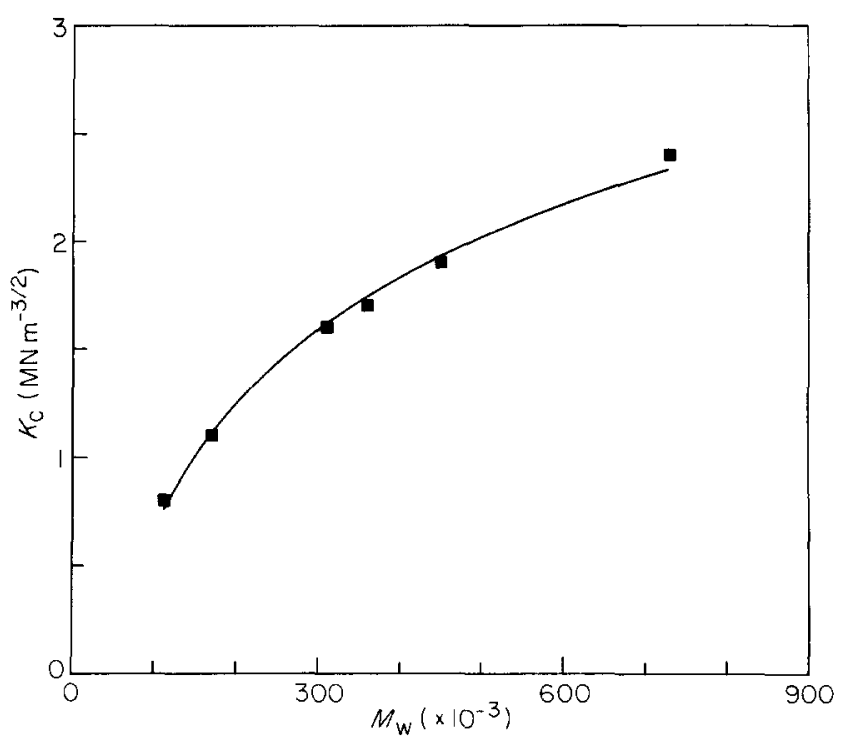

Figure 6 Critical stress intensity factor as a function of molecular weight for quenched iPP samples

increase strongly with increasing molecular weight. The parameter $G_{\mathrm{c}}$, however, seems to be more sensitive to the molecular weight change.

The key to understanding the effect of $M_{\mathrm{w}}$ on fracture toughness is the tie-molecules that join the crystalline blocks together. These molecules act as local transducers of stress among lamellae and spherulites and hence are able to control the deformation and the fracture process. Their mechanical behaviour may be compared with entanglements in amorphous thermoplastics; both are responsible for the fracture strength and without them both types of polymers are extremely weak. The concentration of tie-molecules, first reported by Keith et al. ${ }^{10}$, decreases markedly with decreasing $M_{\mathrm{w}}$. Before a critical molecular weight no tie-molecules could be observed. Therefore, as the number of tiemolecules decreases, the materials become physically less interconnected and hence the applied load becomes concentrated at fewer sites at the surfaces of the crystallites, producing larger stress concentrations. Thus a fracture at lower stress and strain levels may occur. Evidence for the role played by the tie-molecules in controlling the fracture process arises from the fractographic analysis performed on such materials.

Figure 7 shows the scanning electron micrographs after impact failure of some of the quenched iPP samples. All the pictures were taken near the notch tip in the region of crack initiation. The sample with the lowest molecular weight (Figure $7 a$ ) shows a fracture morphology typical of a very brittle material with no signs of localized plastic deformation in the form of crazes or shear bands. Instead, at higher molecular weight (Figures $7 b-d$ ), there is clear evidence of a well-defined plastic region ahead of the notch tip (the notch is situated on the left-hand side of the micrographs) which becomes markedly more extended as the molecular weight is increased. This deformed zone displays morphological features termed 'patch pattern' or 'mackerel', which are frequently reported for amorphous polymers ${ }^{11-13}$, suggesting that the onset of crack propagation is preceded by crazing. These crazes may develop and propagate within spherulites and interspherulite regions and hence their formation is essentially determined by the degree of interconnection existing in the material, which in turn depends on the molecular weight. Previous studies on molecular weight dependence of crazing in amorphous polymers ${ }^{14,15}$ have shown that in the case of high molecular weight polymers, the crazes were very numerous, long and straight. When the molecular weight was lowered, comparatively few, coarse-textured crazes were formed. At very low molecular weight the tendency for craze formation was greatly decreased. For iPP samples, similar results are observed as a consequence of the fact that increasing $M_{\mathrm{w}}$ increases both the inter- and the intraspherulitic link density, so that the crazes formed in one of these regions have enough strength to cause further crazing in their neighbourhood before they break down. Thus, massive crazing with greater stability and resistance to crack propagation can be formed with increasing $M_{w}$. Therefore the greater toughness observed with increasing $M_{\mathrm{w}}$ arises from a larger energy dissipation due to the crazing mechanism.

A similar qualitative result may be obtained by varying undercooling, $\Delta T$, since the structural network (connectivity between crystallites and spherulites), where craze nucleation first takes place, is built up during the crystallization process. Figure 8 shows the effect of $\Delta T$ on the fracture toughness for three different iPP samples, representing low, medium and high molecular weight. The data of Figure 8 show a slight linear enhancement of $G_{\mathrm{c}}$ with increasing $\Delta T$ and for a constant $\Delta T$, as already found, a marked increase of $G_{\mathrm{c}}$ with $M_{\mathrm{w}}$. The modest improvement in fracture toughness observed with $\Delta T$ is due to the limited range of $T_{\mathrm{c}}$ employed and can be attributed to an increased number of tie-chains produced at higher $\Delta T$ values. This assumption can be confirmed by electron microscopy studies conducted on the fractured surfaces.

Figure 9 shows the SEM micrographs of iPP samples crystallized at $\Delta T$ values of 55 and $65^{\circ} \mathrm{C}$. It can be seen from these pictures that some plastic deformations are confined to the spherulite boundaries, which are less crack resistant than the inner zones. This results in interspherulitic craze formation and subsequent boundary fracture. Also, from Figure $7 d$ it appears that the resistance to this type of failure tends to increase with 


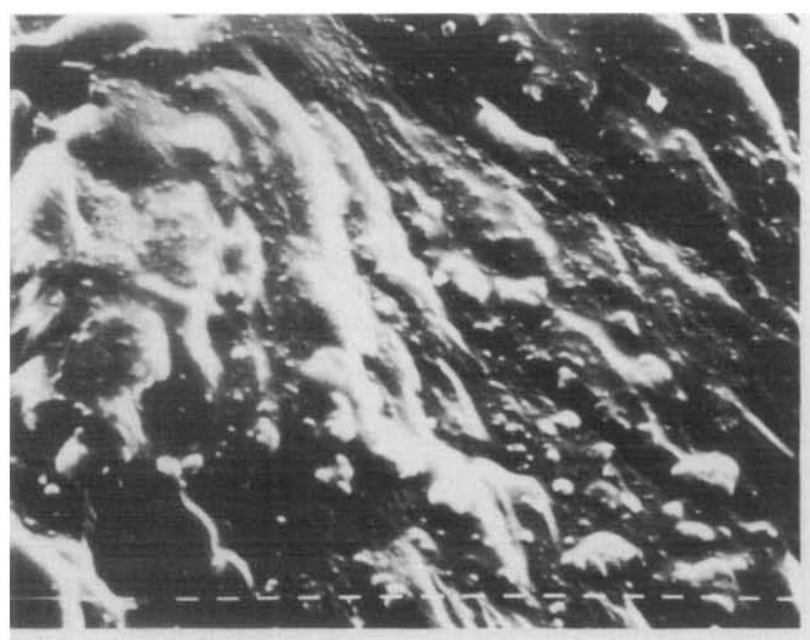

a

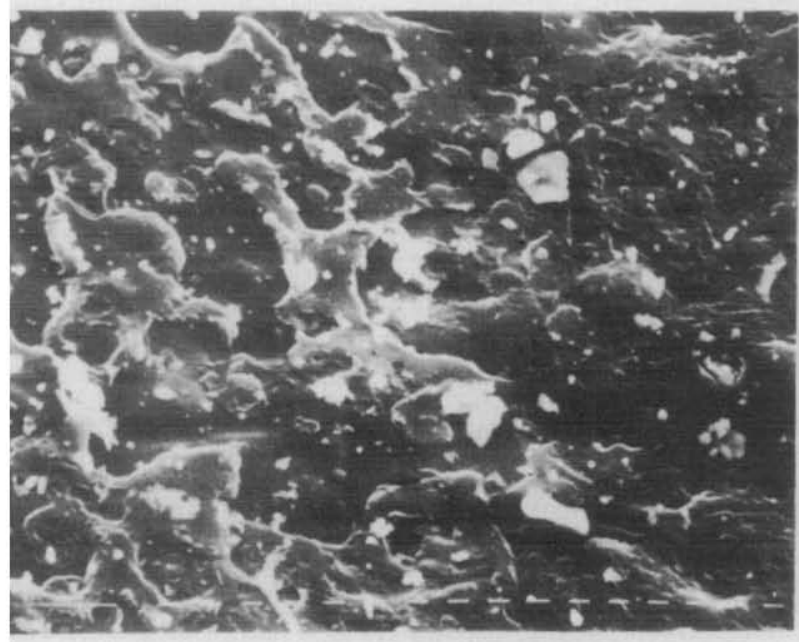

c

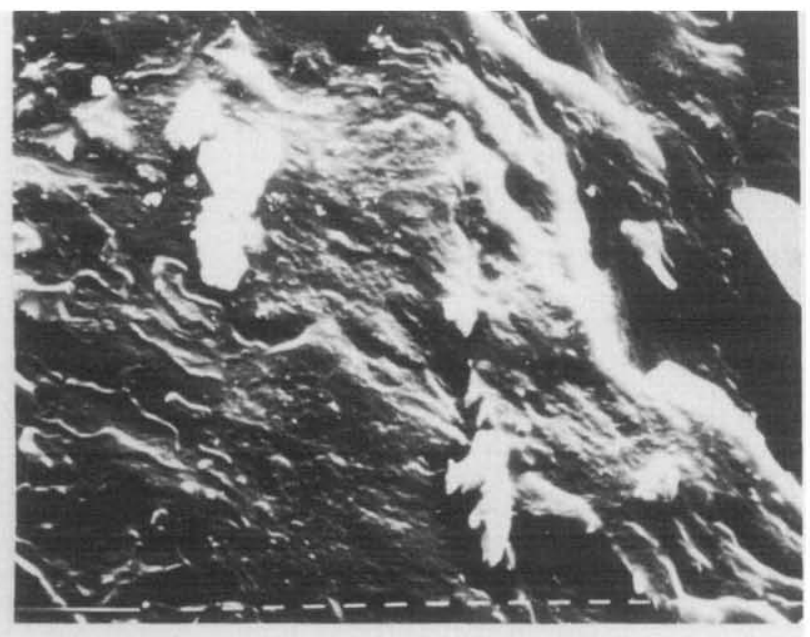

b

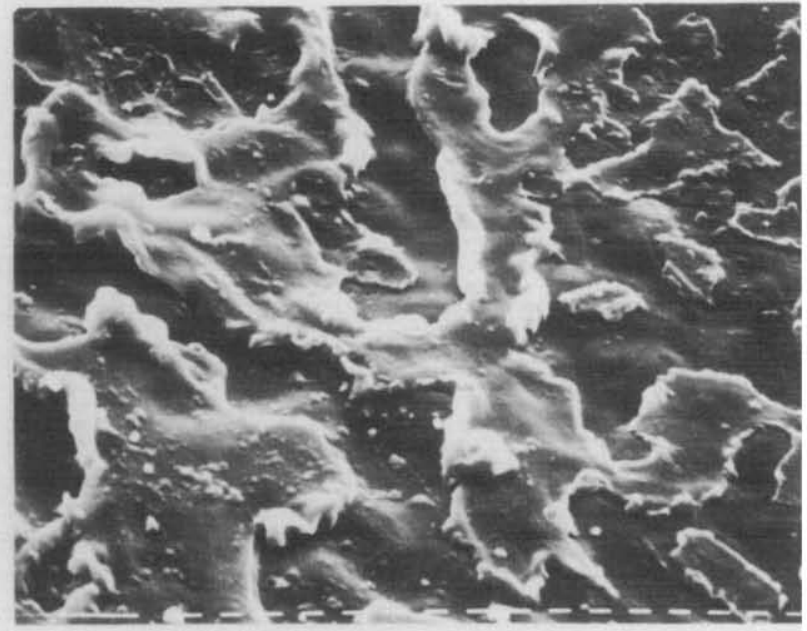

d

Figure 7 Scanning electron micrographs of fractured surfaces of quenched iPP: (a) iPP1; (b) iPP2; (c) iPP3; (d) iPP5

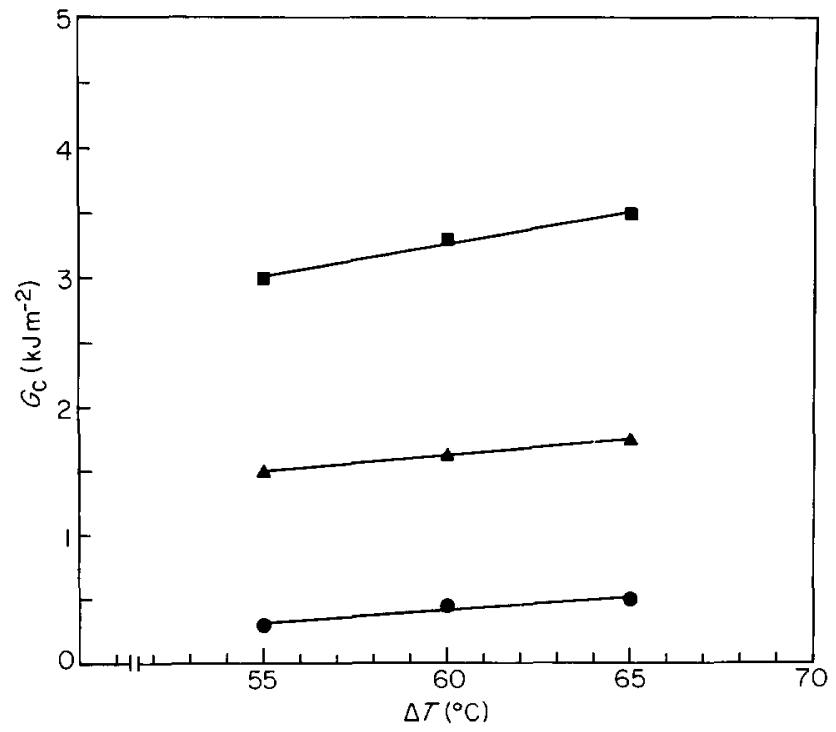

Figure 8 Critical strain energy release rate as a function of undercooling:, iPP1; $\mathbf{A}$, iPP4; $\mathbf{\square}$, iPP6 increasing $\Delta T$. This effect arises from the different structures formed under the different crystallization conditions and depends especially on the quality of the amorphous phase connecting the spherulites. At higher $\Delta T$, the crystallization rate is higher so that poorly crystallized chains can be incorporated. Moreover, since the rate of spherulite growth is greater at large $\Delta T$, small molecules can be trapped more easily between crystallites before they can diffuse away. Therefore, higher $\Delta T$ should produce the best quality boundaries enhancing the tendency for craze formation, especially among spherulite regions. This accounts for the more plastic deformation observed prior to the final fracture at increased $\Delta T$.

The above results have demonstrated that, when the crystallization process is very slow, changes in $\Delta T$ can give only a modest increase in strength of the spherulite boundaries, which are considered to be the major factor in controlling the fracture toughness. Under such crystallization conditions, however, a more substantial improvement of the spherulite boundary properties, without large variation in other structural parameters, 


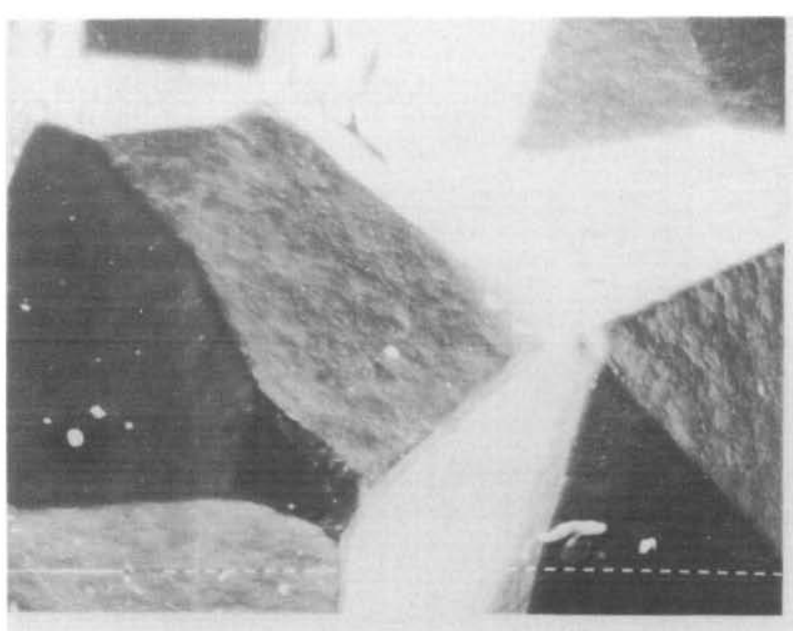

a

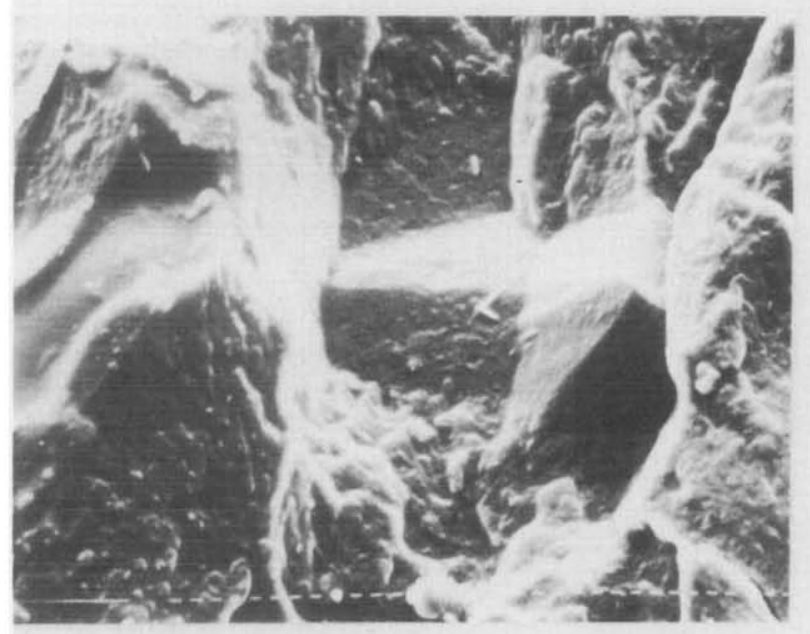

$\mathbf{C}$

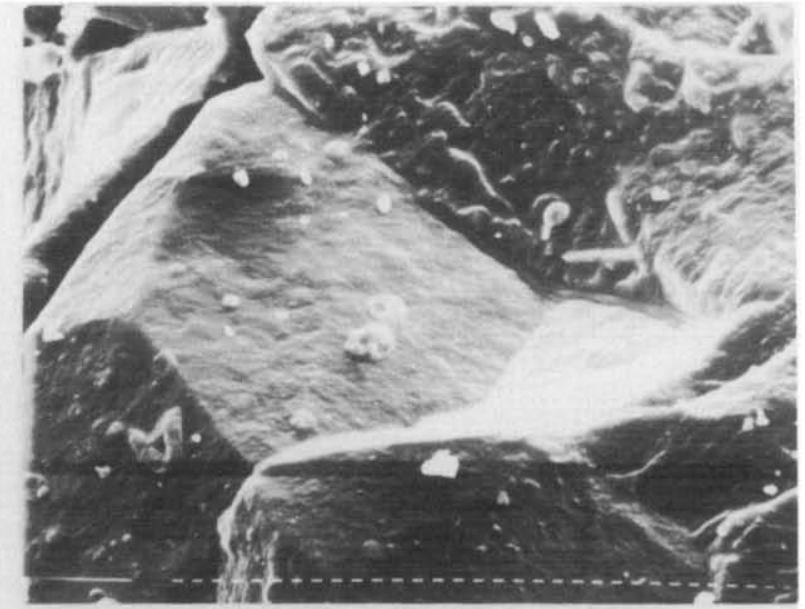

b

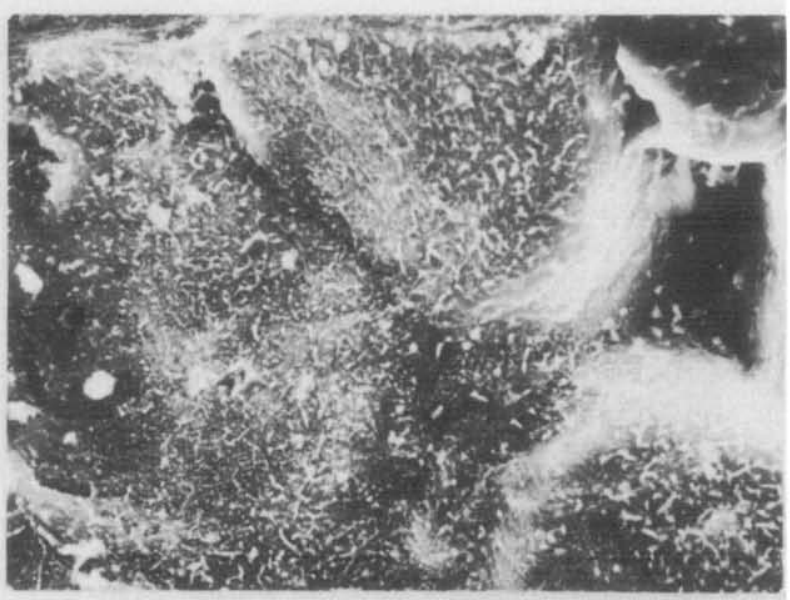

d

Figure 9 Scanning electron micrographs of fractured surfaces of iPP samples at different undercoolings: (a) iPP1, $\Delta T=65^{\circ} \mathrm{C} ;(\mathrm{b})$ iPP1, $\Delta T=55^{\circ} \mathrm{C}$; (c) iPP6, $\Delta T=65^{\circ} \mathrm{C}$; (d) iPP6, $\Delta T=55^{\circ} \mathrm{C}$

can be obtained if nucleating agents are used. Figure 10 shows $G_{\mathrm{c}}$ versus $\Delta T$ for the same iPP samples as in Figure 8 but containing sodium benzoate as nucleating agent. As can be seen, although the general trend of $G_{c}$ is very similar to that of Figure 8 , the values of $G_{c}$, particularly for medium (iPP4) and high (iPP6) molecular weight samples, are much higher. For these samples, in fact, stress whitening was observed just ahead of the notch tip, indicating that extensive plastic deformation has occurred. This may be readily seen from the SEM micrographs of Figure 11 which show the presence of highly stretched material in the region of crack initiation. Such an effect, which increases with increasing $\Delta T$ and $M_{\mathrm{w}}$, is associated with the occurrence of stabilized crazes able to accommodate very large strains before breakdown. A possible explanation of the different fracture behaviour observed when a nucleating agent is added can be found in the role of sodium benzoate in reducing average spherulite size and increasing the formation of tie-molecules. However, as previously reported, crystallinity content and lamellar thickness remain essentially invariant with sodium benzoate.

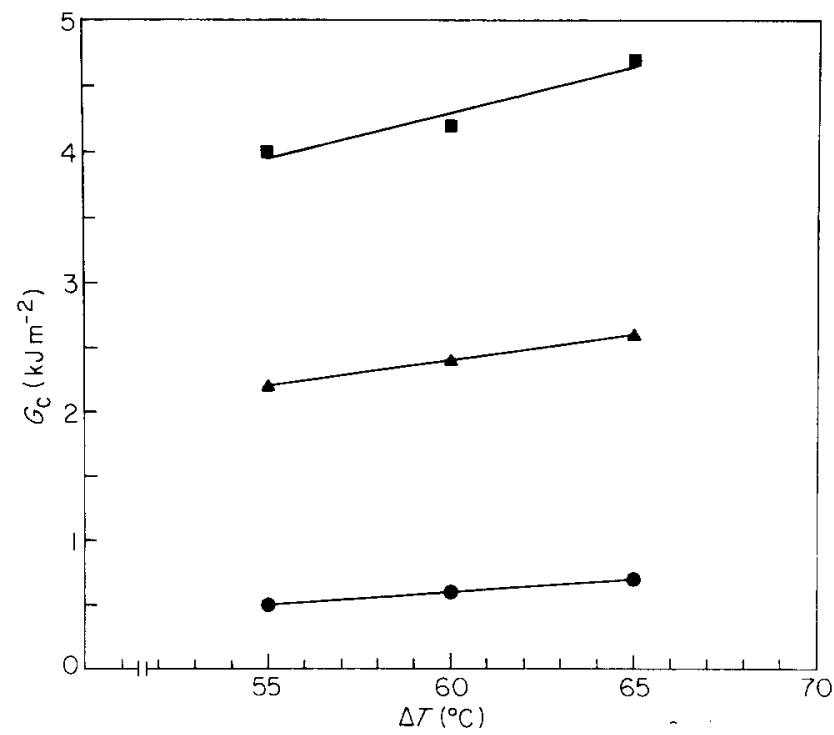

Figure 10 Critical strain energy release rate as a function of undercooling for iPP samples containing sodium benzoate as nucleating agent: $\mathrm{O}$, iPP1: $\boldsymbol{\Delta}, \mathrm{iPP4} \mathbf{\square}$, iPP6 


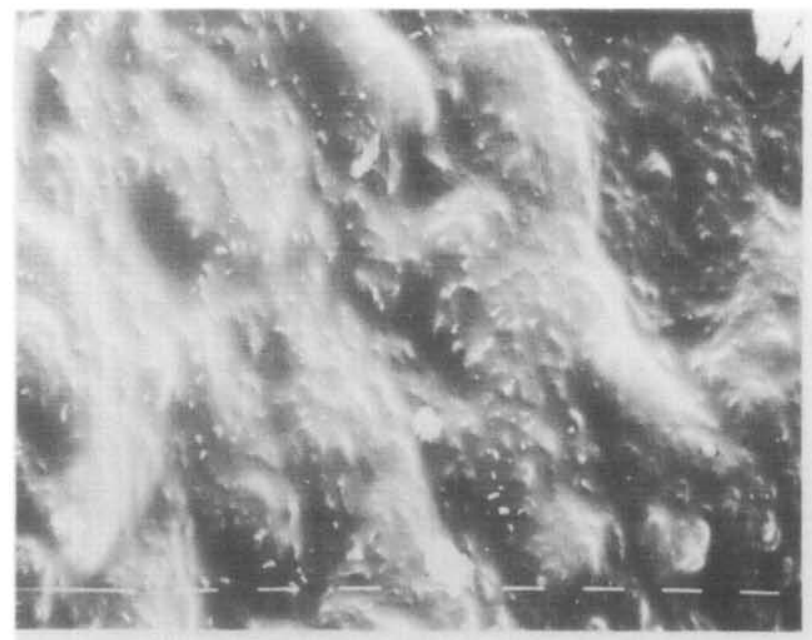

a

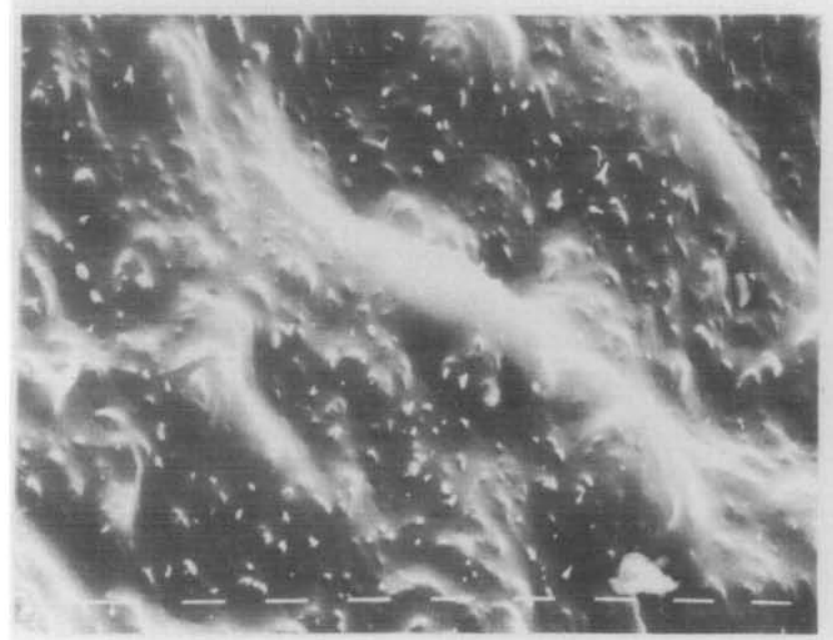

c

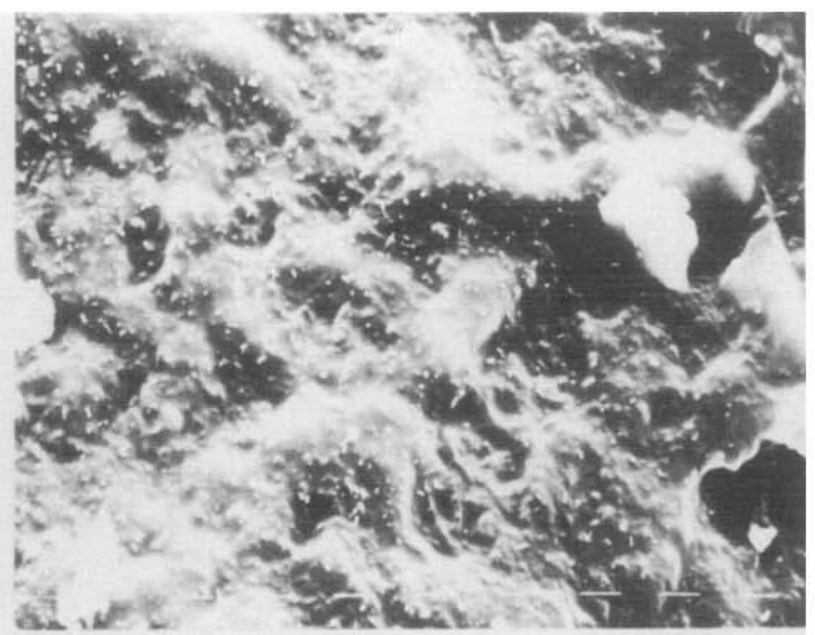

b

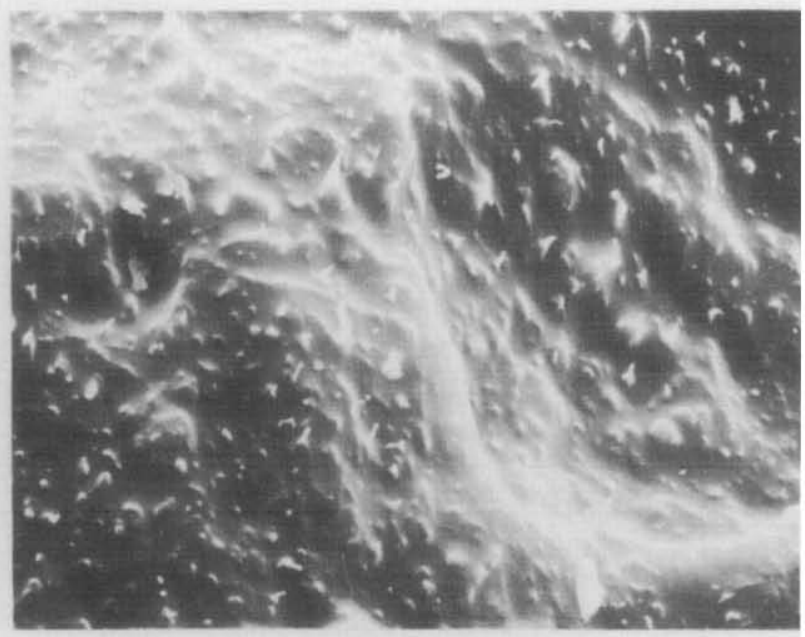

d

Figure 11 Scanning electron micrographs of fractured surfaces at different undercoolings of iPP samples containing sodium benzoate as nucleating agent: (a) iPP4, $\Delta T=65^{\circ} \mathrm{C}$; (b) iPP4, $\Delta T=55^{\circ} \mathrm{C}$; (c) iPP6, $\Delta T=65^{\circ} \mathrm{C}$; (d) iPP6, $\Delta T=55^{\circ} \mathrm{C}$

Previous studies ${ }^{16-18}$ have reported that ductility, yield strength and impact strength are improved with decreasing spherulite size. However, in most of those investigations the spherulite size was varied either by controlling the temperature of isothermal crystallization or by controlling the cooling rate. Under such conditions, variation in other structural entities (link density, crystallinity, lamellar thickness, void formation at spherulite boundaries etc.) can be obtained, hence it is not clear whether the earlier results reflect only spherulite size effects or are also caused by other structural variations. However, the trend of our results seems to indicate that the link density should have a stronger effect than spherulite size on fracture toughness, because we have found that failure is preferentially initiated at interspherulitic boundaries.

\section{Correlation between fracture toughness and superreticular parameters}

The results presented above have shown that the parameter $G_{\mathrm{c}}$ is very sensitive to structural changes in bulk-crystallized PP samples. It can be taken as a measure of the structural interconnections existing in the material. On this basis we have examined the correlation of such a parameter with some structural parameters such as $L$, $L_{\mathrm{a}}$ and $L_{\mathrm{c}}$. This correlation for quenched iPP samples is reported in Figures $12 a-c$. In all cases, an increase of $G_{c}$ is observed with increasing the superreticular parameters. This trend indicates that the crystallite level structure plays a significant role in the fracture process. However, the problem of isolating lamellar-level effects from spherulite-level effects makes it difficult to clearly establish the role of the crystallite texture.

Returning to Figures $12 a$ and $b$, the observed behaviour is due essentially to the fact that with increasing $L$ and $L_{\mathrm{a}}$, the internal spherulite structure becomes more interconnected, enhancing the resistance to crack propagation. Since $G_{c}$ is sensitive to both intra- and interspherulitic link densities, it is reasonable to expect an increase of $G_{\mathrm{c}}$ with increasing $L$ and $L_{\mathrm{a}}$. On the contrary, only the effects of $L_{\mathrm{c}}$ on the fracture toughness (Figure 12c) seem to be apparent. In 

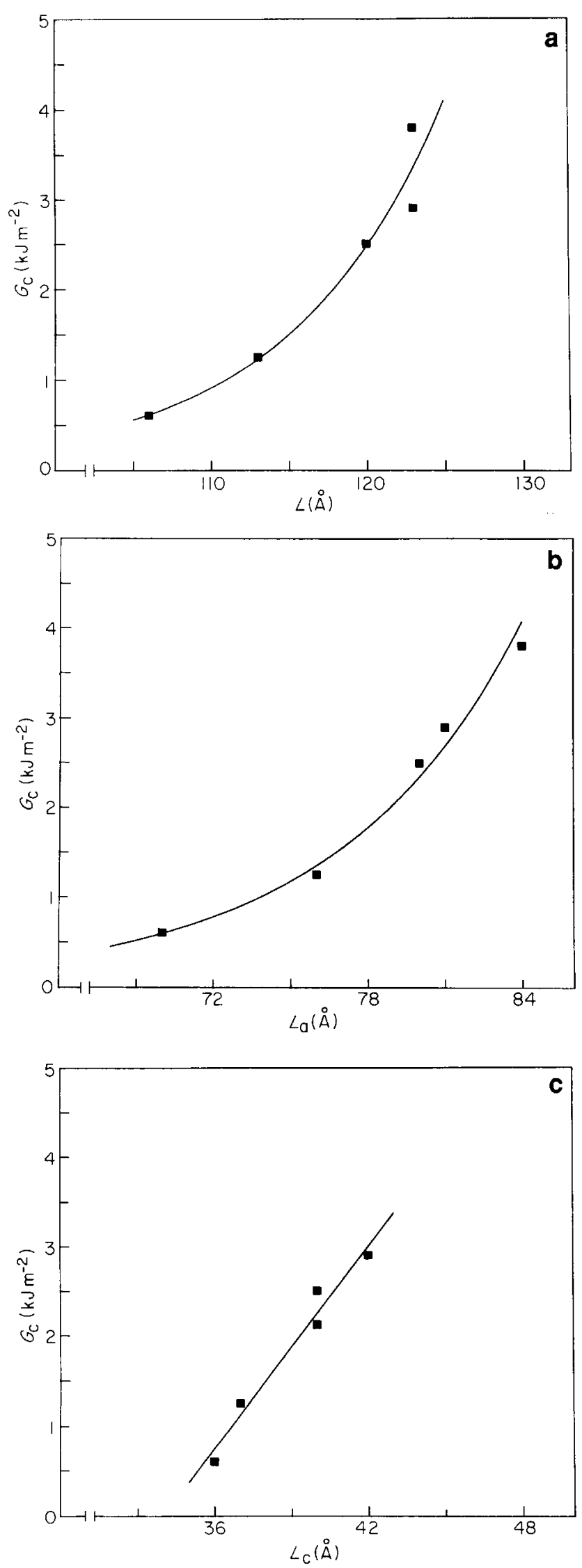

Figure 12 Critical strain energy release rate as a function of (a) long period, (b) amorphous lamellar thickness and (c) crystalline lamellar thickness, for quenched samples

fact, as pointed out previously, the quenching treatment leads to only a very small variation in the $L_{\mathrm{c}}$ values. Therefore, the contribution to the fracture toughness due to the plastic deformation on the crystallites should be almost constant for all the iPP samples. In this way, the controlling parameter of the intraspherulitic fracture is the enhancement of the tie-chains that connect unit areas of adjacent crystallites.

A similar correlation has been made for iPP samples isothermally crystallized with and without a nucleating agent. Figures $13 a$ and $b$ show the results without nucleating agent. For all the investigated undercoolings, $G_{\mathrm{c}}$ appears to increase quite strongly with increasing $L$ and $L_{\mathrm{a}}$. Such behaviour suggests a marked effect of the intraspherulitic structure on $G_{\mathrm{c}}$. This contrasts with the results of fractographic analysis, which have demonstrated that at low undercoolings the crack essentially follows the weak boundaries of the original coarse spherulites. A possible explanation of this disagreement is that the above correlation overestimates the contribution of the internal spherulitic structure. In fact, in such materials the connectivity of the spherulitic boundaries is the major factor in controlling the fracture toughness. Finally, Figures $14 a$ and $b$ report the correlation for isothermally crystallized samples containing a nucleating agent. As we have seen, the trend
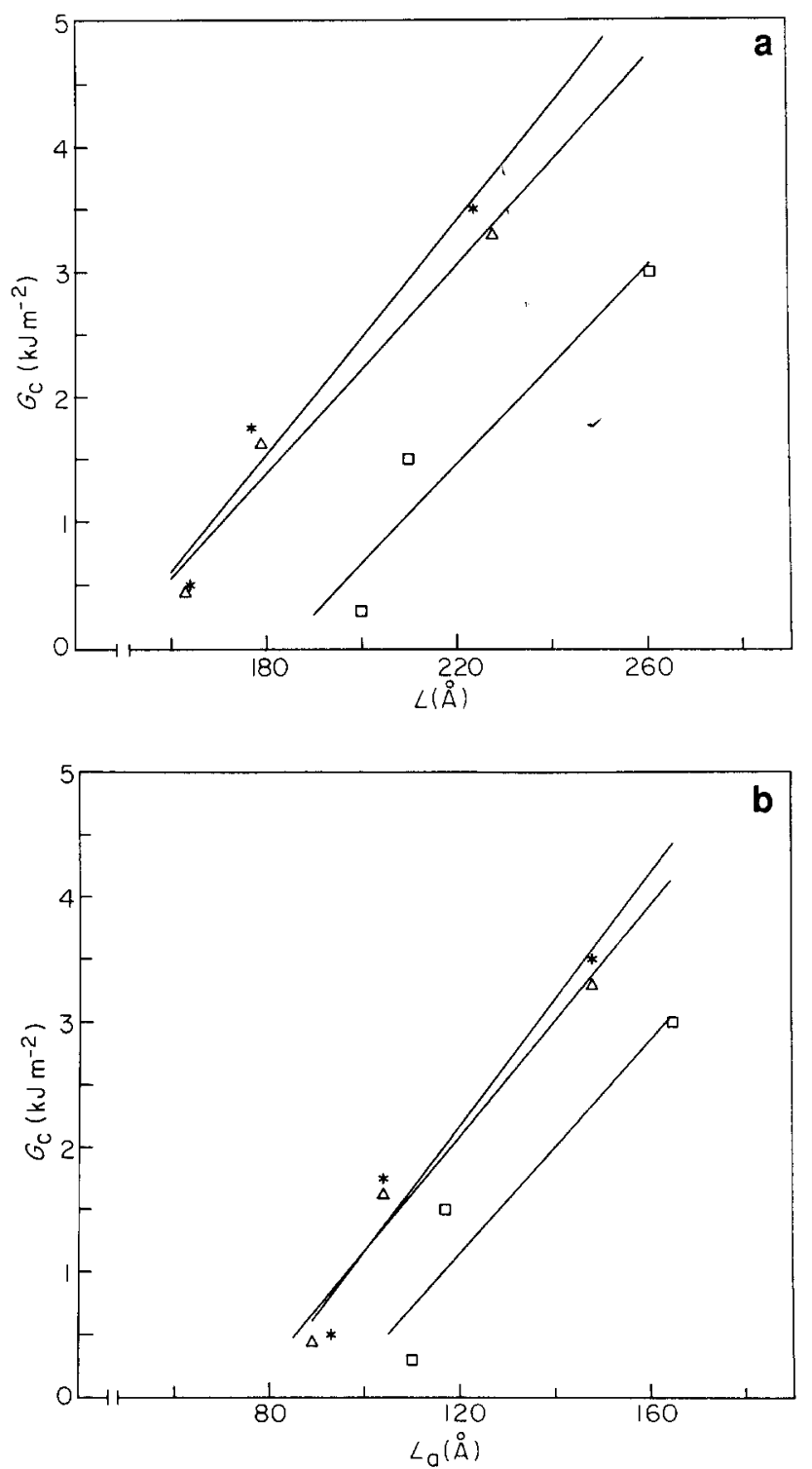

Figure 13 Critical strain energy release rate as a function of (a) long period $\mathrm{L}$ and (b) amorphous lamellar thickness, for isothermal samples at different undercoolings: $*, 65^{\circ} \mathrm{C} ; \triangle, 60^{\circ} \mathrm{C} ; \square, 55^{\circ} \mathrm{C}$ 

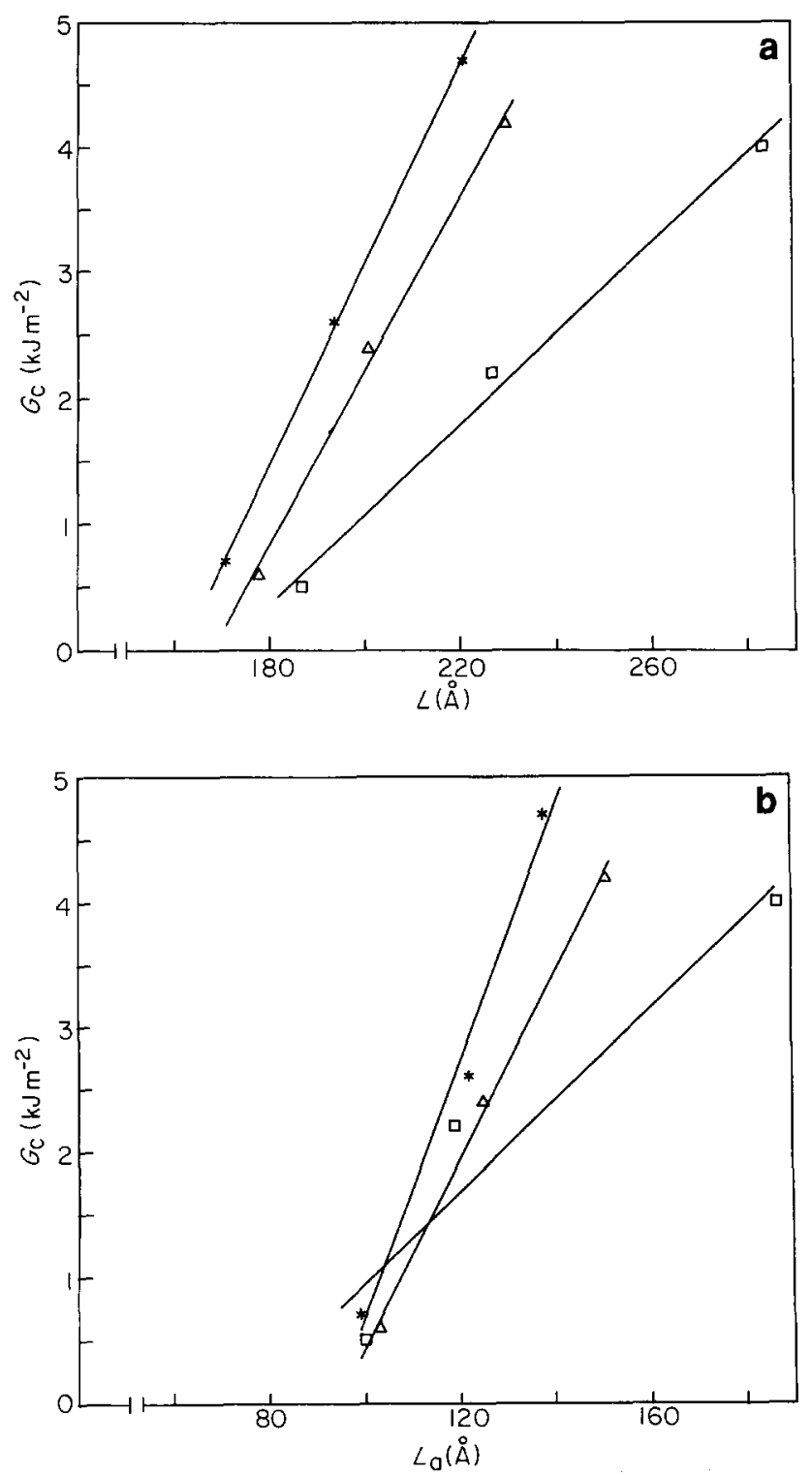

Figure 14 Critical strain energy release rate as a function of (a) long period and (b) amorphous lamellar thickness, for isothermal samples with nucleating agent at different undercoolings: $*, 65^{\circ} \mathrm{C} ; \triangle, 60^{\circ} \mathrm{C} ; \square$, $55^{\circ} \mathrm{C}$

is very close to that observed without a nucleating agent. However, in this case, as for quenched samples, the presence of a very fine spherulitic structure leads to competition between localized interspherulitic fracture and dispersed intraspherulitic fracture. Therefore, it is reasonable to observe a marked dependence of the fracture toughness with parameters such as $L$ and $L_{\mathrm{c}}$.

\section{CONCLUDING REMARKS}

It has been shown that processing conditions and molecular characteristics strongly influence the structure and consequently the high-speed fracture behaviour of isotactic polypropylene. In particular, from the findings presented here the following conclusions can be drawn.

The amount of crystallinity is lowered by increasing undercooling and molecular weight, while the lamellar thickness increases with increasing molecular weight and decreasing undercooling. These effects can be understood on the basis of the molecular mechanism acting during the crystallization process.

The fracture toughness parameters $\left(G_{\mathrm{c}}\right.$ and $\left.K_{\mathrm{c}}\right)$, which represent the resistance of material prior to crack propagation, increase markedly with increasing molecular weight. Moreover, the use of sodium benzoate as a nucleating agent strongly enhances the toughness of the isothermally crystallized samples. These fracture results were interpreted in terms of a fractographic analysis performed by SEM. This analysis demonstrated that the dominant failure mechanism was localized crazing, which occurred to a greater extent as the connectivity between crystallites and spherulites was enhanced.

Finally, the correlation of the fracture toughness with some superreticular parameters has shown the important role played by the crystal-level microstructure on the failure process.

\section{ACKNOWLEDGEMENT}

This work was partly supported by 'Progetto Finalizzato Chimica Fine 2-CNR'.

\section{REFERENCES}

1 Avella, M., dell'Erba, R. and Martuscelli, E. Mackromol. Chem. submitted

2 Galli, P., Simonazzi, T. and Del duca, D. Acta Polym. 1988, 39, 81

3 Brandrup, J. and Immergut, E. M. (Eds) 'Polymer Handbook', Interscience, New York, 1989

4 Glatter, O. J. Appl. Crystallogr. 1974, 7, 147

5 Alexander, L. E. 'X-ray Diffraction in Polymer Science', Wiley, New York, 1969

6 Kinloch, A. J. and Young, R. J. 'Fracture Behaviour of Polymers', Applied Science, London, 1983

7 Brown, W. F. and Srawley, J. ASTM STP 410, American Society for Testing and Materials, Philadelphia, 1966, p. 13

8 Plati, E. and Williams, J. G. J. Polym. Eng. Sci. 1975, 15, 470

9 Martuscelli, E., Canetti, M. and Seves, A. Polymer 1989, 30, 304

10 Keith, H. D., Padden, F. J. Jr and Vadimsky, G. J. Polym. Sci. $A-2$ 1966, 4, 267

11 Greco, R. and Ragosta, G. Plast. Rubber Process. Appl. 1987, 7 , 163

12 Murray, J. and Hull, D. J. Polym. Sci. A-2 1970, 8, 583

13 Van Noort, R. and Ellis, B. J. Mater. Sci. Lett. 1984, 3, 1031

14 Fellers, J. F. and Kee, B. F. J. Appl. Polym. Sci. 1974, 18, 2355

15 Lainchbry, D. L. G. and Bevis, M. J. Mater. Sci. 1976, 11, 2222

16 Lovinger, A. J. and Williams, M. L. J. Appl. Polym. Sci. 1980, 25, 1703

17 Way, J. L., Atkinson, J. R. and Weitting, J. J. Mater. Sci. 1974, 9, 293

18 Kleiner, L. W., Radloff, M. R., Schultz, J. M. and Chon, T. W. J. Polym. Sci., Polym. Phys. Edn 1974, 12, 819 